\title{
Influence of ceramic thickness and light-curing time on the long-term $\mu$ TBS of silica-based ceramic to human dentin
}

Diana Capelli Barca, Dayanne Monielle Duarte Moura, Giovanna de Fátima Alves da Costa, Carlos Augusto Pavanelli, Marco Antonio Bottino \& Rodrigo Othávio Assunção Souza

To cite this article: Diana Capelli Barca, Dayanne Monielle Duarte Moura, Giovanna de Fátima Alves da Costa, Carlos Augusto Pavanelli, Marco Antonio Bottino \& Rodrigo Othávio Assunção Souza (2017) Influence of ceramic thickness and light-curing time on the long-term $\mu$ TBS of silicabased ceramic to human dentin, Journal of Adhesion Science and Technology, 31:15, 1700-1710, DOI: $10.1080 / 01694243.2016 .1274134$

To link to this article: https://doi.org/10.1080/01694243.2016.1274134

曲 Published online: 02 Jan 2017.

Submit your article to this journal $\sqsubset \pi$

Џ Article views: 42

Q View related articles $\asymp$

View Crossmark data $\nearrow$ 


\title{
Influence of ceramic thickness and light-curing time on the long-term $\mu$ TBS of silica-based ceramic to human dentin
}

\author{
Diana Capelli Barcaa , Dayanne Monielle Duarte Mourab (D), Giovanna de Fátima Alves \\ da Costa ${ }^{\mathrm{b}}$, Carlos Augusto Pavanellia, Marco Antonio Bottino ${ }^{\mathrm{a}}$ and Rodrigo Othávio \\ Assunção Souzab
}

aDepartment of Restorative Dentistry, São Paulo State University (UNESP), São Paulo, Brazil; bepartment of Dentistry, Federal University of Rio Grande do Norte (UFRN), Natal, Brazil

\begin{abstract}
To evaluate the influence of ceramic thickness, light-curing time and thermal cycling (TC) on the $\mu$ TBS of a glass ceramic cemented to human dentin. Ninety-six human molars were embedded in acrylic resin and the occlusal surface was sectioned to exposure dentin. Blocks of feldspathic ceramic (Vita PM9) with different thickness $(6 \times$ $6 \times 1 \mathrm{~mm} / 2 \mathrm{~mm} / 3 \mathrm{~mm}$ ) were fabricated with wax pattern and sprue. The blocks and teeth were randomly distributed into 12 groups $(n=$ 8) according to the ceramic thickness (V1: $1 \mathrm{~mm}, \mathrm{~V} 2: 2 \mathrm{~mm}$ and V3: 3 $\mathrm{mm}$ ), light-curing time (40s; 80s), and TC (yes; no). Dentin was etched, washed and dried. The adhesive (Excite, Ivoclar) was applied onto the dentin surface and light-cured (20s), and the ceramic surface was etched with $10 \% \mathrm{HF}$, washed, dried and silanized. The ceramic blocks were cemented to dentin (Variolink II, Ivoclar). The assembly ceramic/ dentin was stored in distilled water $\left(37^{\circ} \mathrm{C} ; 24 \mathrm{~h}\right)$ and sectioned in $\mathrm{X}$ and $Y$ axes to get the sticks. Half of the samples were submitted to TC while the other half underwent micro-tensile bond testing. The data $(\mathrm{MPa})$ were analyzed by 3-way ANOVA and Tukey test (5\%). ANOVA revealed significant interaction among the factors $(p=0.0001)$. Tukey test showed significant higher bond strength for the $2 \mathrm{~mm}$ group $(\mathrm{V} 280 \mathrm{~s}=17.0 \pm 9.1 \mathrm{MPa})$ in comparison to the other groups. V340s TC $(2.7 \pm 6.3 \mathrm{MPa})$ presented lower bond strength, which was similar to the groups V180s TC $(4.6 \pm 4.9 \mathrm{MPa})$ and V240s TC $(5.9 \pm 4.4 \mathrm{MPa})$. Light-curing for 80 s promoted significant higher bond strength of thicker ceramic ( $3 \mathrm{~mm}$ ) than light-curing for $40 \mathrm{~s}$.
\end{abstract}

\section{ARTICLE HISTORY}

Received 30 May 2016

Revised 16 August 2016

Accepted 14 December 2016

\section{KEYWORDS}

Resin cements; ceramic; dentin; light-curing; microtensile

\section{Introduction}

Glass ceramics are well-known because of their advantages in esthetics [1,2], compression strength [3,4], translucency [4,5], and bonding to teeth [6]. Among the glass ceramics, the most commonly indicated are the feldspathic, lithium dissilicate, and fluorapatite zirconia-reinforced lithium silicate [7]. These ceramics are used to fabricate inlays, onlays, veneers and anterior crowns [8]. In these situations, the adhesive cementation increases 
the bond strength and fracture strength of silica-based ceramics, reducing the chances of debonding, adhesive failures and providing longevity for the restorations [9]. However, adhesion depends on the cementation protocol and bond durability at ceramic/cement/ dentine interfaces [9-12].

High survival rates of glass ceramic restorations have been reported in several clinical situations: onlays (92-97\% for 5 years) [13,14], inlays ( $92-80 \%$ for 7 and 8 years, respectively) [15,16] and veneers (96\% for 21 years) [17]. Despite the high survival rates, some failures have been observed in clinical trials, such as crown fractures [18], endodontic problems [13], marginal staining [16], recurrent caries [18] and interface displacement [19,20]. Some factors are related to failures at dentine/ceramic/cement interface, including inappropriate treatment of ceramic surface [9], contamination of bonding interface [21], inappropriate treatment of substrate/dentine or enamel [22], insufficient light-curing of cement $[23,24]$ and restoration thickness [21].

Many authors have studied the relation between those factors and degree of conversion, hardness and bond strength of resin cement. Cho et al. evaluated the effect of thickness $(0.3$, $0.6,0.9$ and $1.2 \mathrm{~mm}$ ) on polymerization of two resin cements (light- and dual-cured) and found that the dual-cured resin cements promoted significantly lower degree of conversion and hardness for the groups with $1.2 \mathrm{~mm}$ [25]. Similarly, Passos et al. (2012) evaluated the bond strength of a feldspathic ceramic cemented to dentine using different cements (lightand dual-cured) and light-curing methods (halogen and LED) under thermal aging. The authors concluded that the light-curing methods influenced bond strength when light-cured cement was used (LED > halogen) [10].

Several studies [26-28] have evaluated the influence of ceramic thickness, cement type and light-curing time on degree of conversion and hardness of resin cement. To reduce clinical time and perform faster procedures, light-curing unit devices evolved over time showing higher irradiance and shorter time exposure while maintaining the effectiveness of the conversion of monomer [28]. However, few studies evaluated the effect of those factors on bond strength of resin cements to dentine [24]. In this sense, the aim of this study was to evaluate the influence of ceramic thickness and light-curing time on micro-tensile bond strength of a glass ceramic cemented to human dentine submitted or not submitted to thermal cycling (TC). The research hypotheses assumed that (1) ceramic thickness is a negative factor for bond strength, (2) light-curing time influences bond strength, and (3) thermal aging reduces bond strength.

\section{Material and method}

Table 1 shows the materials, brands, manufacturers, and chemical compositions used in this study.

\section{Selection and teeth preparation}

This research was approved by the Research Ethics Committee of the Dental School of São José dos Campos, under protocol number 079/2009-PH/CEP. A total of 96 human molars without caries and restorations were cleaned with curettes and stored in distilled water at $18{ }^{\circ} \mathrm{C}$. Each tooth was embedded in self-curing acrylic resin using a silicone mold, and a 
Table 1. Material, manufacturer, chemical composition and lot of the materials used in the study.

\begin{tabular}{|c|c|c|c|}
\hline Material & Manufacturer & Chemical composition & Lot \\
\hline $\begin{array}{l}\text { VITA PM9 } \\
\text { Color: } 2 \mathrm{M} 1 \mathrm{P}-\mathrm{T}\end{array}$ & $\begin{array}{l}\text { Vita Zanhfabrik, Bad Sachingen, } \\
\text { Germany }\end{array}$ & $\begin{array}{l}\text { Si: } 19.6 \% ; \text { Al: } 4.9 \% ; \mathrm{K}: 4.0 \% \text {; Na: } 2.4 \% \text {; Ca: } \\
\text { 0.7\%; C: } 25.7 \% \text { and O: } 42.2 \%\end{array}$ & 15800 \\
\hline $10 \%$ hydrofluoric acid & Dentsply, Petrópolis, RJ, Brazil & $1.0 \mathrm{~g}$ contains: $<5 \%$ hydrofluoric acid & 11666 \\
\hline Monobond & $\begin{array}{l}\text { Ivoclar Vivadent, Schaan, } \\
\text { Leichtenstein }\end{array}$ & Ethanol, water and silane & 31371 \\
\hline $37 \%$ phosphoric acid & $\begin{array}{l}\text { Ivoclar Vivadent, Schaan, } \\
\text { Leichtenstein }\end{array}$ & $\begin{array}{l}37 \% \text { phosphoric acid, thickening agent } \\
\text { containing pyrogenic silica and } \\
\text { surfactant }\end{array}$ & 240909 \\
\hline Variolink II - color: clear & $\begin{array}{l}\text { Ivoclar Vivadent, Schaan, } \\
\text { Leichtenstein }\end{array}$ & $\begin{array}{l}\text { Paste of dimethacrylates (BisGMA, } \\
\text { UEDMA, TEGDMA), benzoylperoxide, } \\
\text { ytterbium trifluoride, inorganic fillers, } \\
\text { initiators, stabilizers, pigment }\end{array}$ & L38887 \\
\hline Excite & $\begin{array}{l}\text { Ivoclar Vivadent, Schaan, } \\
\text { Leichtenstein }\end{array}$ & $\begin{array}{l}\text { Dimethacrylates, alcohol, phosphonic } \\
\text { acid acrylate, } \mathrm{HEMA} \mathrm{SiO}_{2} \text {, initiators, } \\
\text { stabilizers }\end{array}$ & M61177 \\
\hline
\end{tabular}

surveyor was used to maintain the occlusal surface parallel to the resin base. The occlusal surface was then sectioned to expose dentine (Labcut 1010, Erios - equipamento técnicos e científicos LTDA, São Paulo, Brazil). The surface was planed and polished with sandpaper \# 1200 (3 M, St. Paul, USA) in a polisher (Labpol 8-12, Extec, USA) to standardize the dentine substrate. The teeth were stored in water at $37^{\circ} \mathrm{C}$ for $24 \mathrm{~h}$ before the cementation process was initiated.

\section{Fabrication of ceramic blocks}

Sixteen wax patterns were fabricated for each dimension: $6 \times 6 \times 1 \mathrm{~mm}, 6 \times 6 \times 2 \mathrm{~mm}$ and $6 \times 6 \times 3 \mathrm{~mm}$; totaling 48 blocks. The sprues were fixed to the wax patterns and the assembly (pattern/sprue) was embedded in an investment ring. After wax evaporation, the ceramic ingots (VITA PM9, color 2M1P-T, VITA Zanhfabrik) were fused and injected according to the manufacturer's instructions (EP 600, Ivoclar Vivadent Inc. Amherst, NY, USA).

Next, the ceramic blocks were divested and sandblasted with aluminum oxide in order to remove any investment residue. After sandblasting, the excess ceramic blocks were removed with diamond discs at low speed (KG- Sorensen) and the surface for cementation was planed and polished with sandpaper \# 600, 800 and 1200 (3 M ESPE, St. Paul, USA). Thus, the sandblasted surfaces were completely removed and standardized after polishing. The blocks were submitted to different cementation protocols according to each experimental group (Table 2).

\section{Treatment of dentine surface}

The tooth surface was etched with $37 \%$ phosphoric acid (Ivoclar Vivadent, Schaan, Leichtenstein) for 15s, washed for 20s and dried with absorbent paper. Then, a light-cured adhesive system (Excite F, Ivoclar Vivadent) was applied with a disposable applicator according to the manufacturer's instructions and light-cured for 20s (Radii-cal, SDI Limited, Australia, $1200 \mathrm{~mW} / \mathrm{cm}^{2}$ ). 
Table 2. Experimental groups based on ceramic thickness (3 levels), light-curing time ( 2 levels) and thermal cycling (TC) (2 levels).

\begin{tabular}{|c|c|c|c|}
\hline Group & Ceramic thickness & Light-curing time & Thermal cycling \\
\hline $\bar{V} 1_{40 s} \mathrm{TC}$ & $1 \mathrm{~mm}$ & $40 \mathrm{~s}$ & $\begin{array}{l}\text { YES } \\
\text { NO }\end{array}$ \\
\hline $\begin{array}{l}\mathrm{V} 1_{40 \mathrm{~s}} \\
\mathrm{~V}{ }^{20 \mathrm{~s}} \mathrm{TC}\end{array}$ & $2 \mathrm{~mm}$ & & YES \\
\hline $\mathrm{V} 2_{40}^{405}$ & & & NO \\
\hline $\mathrm{V} 3_{40,5} \mathrm{TC}$ & $3 \mathrm{~mm}$ & & YES \\
\hline $\mathrm{V}_{40}{ }_{40}$ & & & NO \\
\hline $\mathrm{V}_{80 \mathrm{~s}}^{40} \mathrm{TC}$ & $1 \mathrm{~mm}$ & $80 \mathrm{~s}$ & YES \\
\hline $\mathrm{V} 1_{80 \mathrm{~s}}$ & & & NO \\
\hline $\mathrm{V}_{80 \mathrm{~s}} \mathrm{TC}^{\mathrm{os}}$ & $2 \mathrm{~mm}$ & & YES \\
\hline $\mathrm{V}_{80} \mathrm{ous}$ & & & NO \\
\hline $\mathrm{V}_{300 \mathrm{~s}} \mathrm{TC}$ & $3 \mathrm{~mm}$ & & YES \\
\hline$V 3_{80 s}^{\text {os }}$ & & & NO \\
\hline
\end{tabular}

\section{Treatment of ceramic surface}

The ceramic blocks were previously cleaned in ultrasonic bath (Vitasonic, Vita Zahnfabrik, Germany) with distilled water for $5 \mathrm{~min}$. Next, the surface for cementation was etched with $10 \%$ hydrofluoric acid (Ivoclar Vivadent, NY, USA) for $1 \mathrm{~min}$, washed with water for 20s and cleaned in ultrasonic bath for $5 \mathrm{~min}$. Finally, the blocks were air-dried for 30s and silanized (Monodond-S, Ivoclar, Vivadent, NY, USA) according to the manufacturer's instructions.

\section{Adhesive cementation}

After dentine etching, the teeth were positioned into a metallic device to standardize the bonding area and the compressive force applied on the ceramic block during cementation. Resin cement (Variolink II, Ivoclar Vivadent, NY, USA) was manipulated for 10s with equal amount of base and catalyst and then applied on the ceramic block surface. The blocks were positioned on dentine and the device was closed to maintain the lateral surfaces away from light. Subsequently, a load of $750 \mathrm{~g}$ was exerted on the ceramic block using a torque wrench for $1 \mathrm{~min}$ [29]. Light-curing of the cement (Radii-cal, SDI, $1200 \mathrm{~mW} / \mathrm{cm}^{2}$ ) was conducted according to each experimental group (40s or 80 s), perpendicular to the surface cementing. The samples were then washed with air-water spray and stored in distilled water at $37^{\circ} \mathrm{C}$ for $24 \mathrm{~h}$.

\section{Sectioning of the assembly and samples preparation}

The tooth/ceramic assembly was sectioned by a saw (Labcut 1010) under low speed and constant water refrigeration. The interface was positioned perpendicular to the diamond disc (Extec, Enfiel) in order to get rectangular sticks with non-trimmed interface and adhesive interface with area about $1 \mathrm{~mm}^{2}$ [30,31]. All sticks of each tooth/ceramic assembly were stored in distilled water at $37^{\circ} \mathrm{C}$ in an incubator for $24 \mathrm{~h}$.

\section{Thermal cycling}

The sticks of each tooth/ceramic assembly were randomly distributed into two groups, according to the storage condition: no TC (dry) - stick submitted to micro-tensile bond 
test $24 \mathrm{~h}$ after cutting; TC - stick submitted to TC $\left(12,000\right.$ cycles, $\left.5{ }^{\circ} \mathrm{C} / 55^{\circ} \mathrm{C}, 30 \mathrm{~s}\right)$ and micro-tensile bond test immediately after TC.

\section{Micro-tensile bond testing}

The area of all sticks was measured before testing using a digital caliper. Each stick was fixed with cyanoacrylate glue parallel to the long axis of the micro-tensile test device in order to minimize torsion at the adhesive zone. The device was fixed in a universal testing machine (EMMIC DL-1000, São José dos Pinhais, Brazil) and the test was conducted at $1 \mathrm{~mm} / \mathrm{min}$ under $10 \mathrm{~kg} \mathrm{f}$.

Bond strength was calculated according to the formula $R=F / A$, where $R$ is resistance, $F$ is load to rupture $(\mathrm{N})$ and $A$ is interfacial area $\left(\mathrm{mm}^{2}\right)$.

\section{Fracture analysis}

All the tested sticks were analyzed under optical microscopy (Mitutoyo, Japan) with an increase of $50 \%$ to determine the pattern of failure at the ceramic/cement/tooth interface.

The failures were classified in four types: (1) adhesive (A): fracture at the interface between cement and ceramic or between cement and dentin; (2) dentine cohesive fracture (CD); (3) ceramic cohesive fracture (CC); (4) Combined (M): combined adhesive fracture with dentine or ceramic cohesive fracture.

\section{Statistical analysis}

Data of bond strength was analyzed by 3-way analysis of variance and Tukey test at 5\% level of significance using the software Statistix 8.0 for Windows (Analytical Software Inc., Tallahassee, FL, USA).

\section{Results}

Bond strength of $2 \mathrm{MPa}$ was assumed for those samples exhibiting failure previous to the test since the micro-tensile bond test does not detect values lower than $4 \mathrm{MPa}$ [32]. Thus, the samples lost during cutting and TC were included in the statistical analysis for comparison between the materials. Table 3 shows a high number of pre-test failures in the $\mathrm{V} 3_{40 \mathrm{~s}} \mathrm{TC}$ group, while the $\mathrm{V} 2_{80 \text { s }}$ group presented less frequent occurrence.

ANOVA revealed that bond strength was significantly influenced by light-curing time $(p=0.0001 ; 40 \mathrm{~s}: 6.2 ; 80 \mathrm{~s}: 8.7)$, ceramic thickness $(p=0.0001)$ and TC $(p=0.0001 ; 5.7)$. Significant interaction was also found between thickness and TC $(p=0.0001)$; thickness and light-curing time $(p=0.0001)$; TC and light-curing time $(p=0.0003)$; and thickness, TC and light-curing time ( $p=0.0001)$ (Table 4$)$.

According to the Tukey test, the V280s group (17 $\pm 9.1 \mathrm{MPa})$ showed significantly higher bond strength than the other groups, ranging from 2.7 to $9.4 \mathrm{MPa}$. The $\mathrm{V} 3_{40 \text { s }}$ TC group $(2.7 \pm 6.3 \mathrm{MPa})$ presented the lowest bond strength, which was similar to the $\mathrm{V} 1_{80 \mathrm{~s}} \mathrm{TC}$ $(4.6 \pm 4.9 \mathrm{MPa})$ and $\mathrm{V} 2{ }_{40 \mathrm{~s}}$ TC groups $(5.9 \pm 4.4 \mathrm{MPa})$ (Table 5). 
Table 3. Number $(N)$ and percentage (\%) of samples that exhibited pre-test failures (PTF) during cutting and/or thermal cycling (TC) and total number $(N)$ of samples submitted to micro-tensile bond test (MTBs).

\begin{tabular}{|c|c|c|c|}
\hline Groups & $N$ & $N$ and $\%$ of PTF during cutting and TC & Total $N$ and $\%$ of samples tested \\
\hline $\mathrm{V} 1_{40 \mathrm{~s}} \mathrm{TC}$ & 80 & $36(45)$ & $44(55)$ \\
\hline $\mathrm{V} 1_{40 \mathrm{~s}}^{40 \mathrm{~s}}$ & 80 & $40(60)$ & $40(50)$ \\
\hline $\mathrm{V} 2_{40 \mathrm{~s}}^{40 \mathrm{~s}} \mathrm{TC}$ & 80 & $41(59)$ & $39(48.8)$ \\
\hline $\mathrm{V} 22_{40}^{40 \mathrm{~s}}$ & 80 & $27(73)$ & $53(66.25)$ \\
\hline $\mathrm{V} 3_{40 \mathrm{~s}} \mathrm{TC}$ & 80 & $73(27)$ & $7(8.75)$ \\
\hline$V 3_{40 s}^{40 s}$ & 80 & $52(48)$ & $28(35)$ \\
\hline $\mathrm{V} 1_{80 \mathrm{~s}}^{40 \mathrm{~S}} \mathrm{TC}$ & 80 & $60(40)$ & $20(25)$ \\
\hline $\mathrm{V} 1_{80 \mathrm{~s}}^{805}$ & 80 & $29(71)$ & $51(63.75)$ \\
\hline $\mathrm{V} 2_{80 \mathrm{~s}}^{80 \mathrm{~s}} \mathrm{TC}$ & 80 & $53(55)$ & $27(33.75)$ \\
\hline$V 2_{80}^{\circ 05}$ & 80 & $8(92)$ & $72(90)$ \\
\hline $\mathrm{V} 3_{80 \mathrm{~s}}^{80} \mathrm{TC}$ & 80 & $29(71)$ & $51(63.75)$ \\
\hline$V_{305}$ & 80 & $45(55)$ & $25(31.25)$ \\
\hline
\end{tabular}

Table 4. Analysis of variance (3 factors) for bond strength data (MPa).

\begin{tabular}{lrrrrr}
\hline Effect & DF & \multicolumn{1}{c}{ SS } & MS & \multicolumn{1}{c}{ F } & $p$ \\
\hline Thermal cycling & 1 & 2917.7 & 2917.68 & 60.67 & $0.0001^{*}$ \\
Thickness & 2 & 2177.5 & 1088.75 & 22.64 & $0.0001^{*}$ \\
Light-curing time & 1 & 1530.4 & 1530.43 & 31.82 & $0.0001^{*}$ \\
Thickness $\times$ Thermal cycling & 2 & 1258.1 & 629.04 & 13.08 & $0.0001^{*}$ \\
Thermal cycling $\times$ Time & 1 & 639.3 & 639.34 & 13.29 & $0.0003^{*}$ \\
Thickness $\times$ Time & 2 & 954.2 & 477.12 & 9.92 & $0.0001^{*}$ \\
Thickness $\times$ Thermal cycling $\times$ Time & 2 & 1224.8 & 612.42 & 12.73 & $0.0001^{*}$ \\
Residue & 948 & $45,589.8$ & 48.09 & & \\
Total & 959 & $56,291.9$ & & & \\
\hline
\end{tabular}

*statistical significance $(p<0.05)$.

Table 5. Mean and standard deviation of bond strength (MPa) for each group according to the factors: thermal cycling (TC), light-curing time and ceramic thickness. (Tukey test, $a=0.05$ ).

\begin{tabular}{lcccc}
\hline & \multicolumn{3}{c}{ Time } \\
\cline { 2 - 5 } Thickness & DRY & $40 \mathrm{~s}$ & TC & DRY \\
\hline $1 \mathrm{~mm}$ & $7.1( \pm 7.6)^{B C D}$ & $7.4( \pm 6.9)^{B C D}$ & $9.4( \pm 6.9)^{B}$ & $4.6( \pm 4.9)^{D E}$ \\
$2 \mathrm{~mm}$ & $8.8( \pm 8.1547)^{B C}$ & $5.9( \pm 4.4)^{B C D E}$ & $17( \pm 9.1)^{A}$ & $6.5( \pm 7.9)^{B C D}$ \\
$3 \mathrm{~mm}$ & $5.7( \pm 6.3624)^{C D}$ & $2.7( \pm 6.3)^{E}$ & $7.6( \pm 8)^{B C D}$ & $7.6( \pm 6.3)^{B C D}$ \\
\hline
\end{tabular}

$(p<0.05)$.

According to the analysis of fractured surfaces of the tested specimens, it can be seen that the predominant failure mode is the mixed type. $\mathrm{V} 1_{40 \mathrm{~s}} \mathrm{TC}$ and $\mathrm{V} 1_{40 \text { s }}$ groups had lower adhesion resistance values and a large amount of cohesive ceramic failure.

\section{Discussion}

Adhesive cementation of metal-free prostheses can be influenced by inappropriate polymerization of cement $[33,34]$, which depends on color, opacity and thickness of the ceramic [35,36], as well as polymerization method and time [37]. The association of those factors with clinical conditions such as occlusal stress [22] and thermal variation [38], tends to reduce bond strength at dentine/ceramic/cement interface, leading to restoration displacement. 
In this sense, several methods have been suggested to assess bond strength at adhesive interfaces including shear [39], micro-shear [40], tensile [41], and micro-tensile [42] testing. Although shear testing is commonly used to evaluate adhesion between several substrates because of its simplicity and ease, cohesive failures are frequently observed with this method. Also, data is influenced by non-uniform distribution of stress which is driven towards the material base instead of an adhesive interface as a result of adhesive areas being larger than $2.0 \mathrm{~mm}^{2}\left(7-11 \mathrm{~mm}^{2}\right)$ [43]. As a consequence, micro-tensile testing has been widely used to demonstrate the real adhesive force existing between different substrates, while less superficial failures and defects at the adhesive zone are observed [30,44]. Sano et al. [44] demonstrated the inversely proportional relation between adhesive area and bond strength when a reduction in testing area $\left(<2.0 \mathrm{~mm}^{2}\right)$ resulted in higher bond strength. In addition, adhesive failure was the most common fracture pattern observed, which means that no cohesive fracture occurred in the substrates. Thus, micro-tensile bond test was selected as an appropriate and advantageous method to evaluate the adhesive interfaces in this study.

According to the results, the hypothesis about a negative influence of ceramic thickness on bond strength was accepted. The groups with thicker ceramics $\left(\mathrm{V} 3_{40 \mathrm{~s}}, \mathrm{~V} 3_{40 \mathrm{~s}} \mathrm{~T}, \mathrm{~V} 3_{80 \mathrm{~s}}\right.$ and $\mathrm{V} 3_{80 \mathrm{~s}}$ TC) exhibited lower bond strength at cement/dentine interface. A thicker ceramic probably reduced light intensity at the adhesive interface and affected cement polymerization [45]. Cho et al. stated that appropriate polymerization of resin cements is limited to a maximum thickness of $1.2 \mathrm{~mm}$, so light-curing time or intensity should be increased for ceramics thicker than $0.9 \mathrm{~mm}$. On the other hand, the present study showed worse performance for the $1 \mathrm{~mm} / 80$ s group in comparison to the $2 \mathrm{~mm} / 80 \mathrm{~s}$ group. However, all groups with $1 \mathrm{~mm}$-ceramic presented cohesive failure within the ceramic. This fact that can be explained by irregular and porous ceramic surfaces created by etching with hydrofluoric acid [22]. Furthermore, the fragility of $1 \mathrm{~mm}$-samples probably caused cracks in the ceramic during the stick cutting and affected the bond strength of this group [46].

When the fractured surfaces of the tested samples were analyzed, it was observed that the predominant failure mode was the mixed type. However, the $1 \mathrm{~mm}$ groups showed a greater number of cohesive ceramic failures due to the small tile thickness $(1 \mathrm{~mm})$. This occurred during cutting due to the cutting saw vibration causing cracks in the ceramic structure, making it more friable.

The hypothesis assuming that light-curing time influences bond strength was accepted. In the present study, the highest bond strength was found in all groups submitted to longer polymerization $\left(\mathrm{V} 1_{80 \mathrm{~s}}, \mathrm{~V} 2_{80 \mathrm{~s}}\right.$ and $\left.\mathrm{V} 3_{80 \mathrm{~s}}\right)$, even after TC. Some studies have suggested longer polymerization [47] and high intensity light sources for cementation of thicker ceramic restorations [10] to manage the negative effect of ceramic thickness. This occurs because increasing the time of exposure to light promotes a higher degree of polymerization, and a higher conversion degree of dual resin cement monomers [47]. According to Rasetto et al. [48], light-curing of resin cements for ceramic restorations can be incomplete when low intensity polymerization units are used [48]. In this sense, ISO recommends light intensity of $300 \mathrm{~mW} / \mathrm{cm}^{2}$ and thickness of $1.5 \mathrm{~mm}$ [49]. The light intensity used for polymerization in this study was $1000 \mathrm{~mW} / \mathrm{cm}^{2}$.

Lopes et al. evaluated the mechanical properties of different resin cements light-cured for $120 \mathrm{~s}\left(650 \mathrm{~mW} / \mathrm{cm}^{2}\right)$ through ceramic discs (feldspathic ceramic, lithium dissilicate and zirconia veneered with feldspathic ceramic) with $1.5 \mathrm{~mm}$ thickness. The feldspathic ceramics exhibited deeper light transmission, while the other ceramics showed loss of energy 
ranging from 11 to $22 \%$. The authors found that light-curing time (120s) can manage the energy density reduction of the ceramics, which affects cement toughness. Thus, longer light-curing can be conducted to enhance polymerization of a dual-cured cement when a thicker ceramic system exhibiting minor light transmission is used [50].

The hypothesis assuming that thermal aging reduces bond strength was accepted. Adhesion between ceramic and cement is susceptible to thermal, chemical and mechanical conditions within an oral environment, so storage in water at a constant temperature and/or TC is frequently used to simulate material adhesion aging [47]. All groups experiencing TC showed reduction in bond strength, most likely as a consequence of hydrolytic degradation of cement/ceramic interface and degradation of the resin cement due to failure between the matrix and inorganic particles [51]. In addition, the substrates (teeth, ceramic and cement) present different coefficients of linear thermal expansion which causes stress and fatigue at adhesive interface when clinical conditions (high and low temperatures during TC) are simulated [32,52]. According to Özcan et al. [22], resin materials absorb water during storage over time and a period of days or weeks are required to achieve maximum absorption. Previous studies evaluating the influence of water absorption on bond strength of resin cements to dentine also found that TC was a negative effect for the experimental conditions $[9,10,47]$.

Thus, within the limitations of this study, further research is required to assess the bond strength of resin cements to dentine regarding ceramic thickness in order to clinically evaluate and validate the parameters used in this study.

\section{Conclusion}

According to the methods, results and limitations of this study, it was concluded that:

(1) Thermal cycling was a negative effect for bond strength in all light-curing times used in this study.

(2) Light-curing for 80 s increased the bond strength between cement/dentine/ceramic in comparison to light-curing for 40 s.

(3) Significant increase in bond strength was achieved with light-curing for 80 s in comparison to $40 \mathrm{~s}$, when a thicker ceramic $(3 \mathrm{~mm})$ was used.

\section{Clinical relevance}

Longer light-curing (80s) must be conducted for polymerization of dual-cured resin cements when glass ceramic restoration with $3 \mathrm{~mm}$ in thickness is used in order to manage the reduction of light intensity at the adhesive interface.

\section{Acknowledgements}

This study was based on a Master Thesis submitted to the Dental School of São Paulo State University (UNESP), São José dos Campos, SP, Brazil as part of the requirements for a MSc degree.

\section{Disclosure statement}

No potential conflict of interest was reported by the authors. 


\section{ORCID}

Dayanne Monielle Duarte Moura (D) http://orcid.org/0000-0003-2111-5205

\section{References}

[1] Nordahl N, Vult von Steyern P, Larsson C. Fracture strength of ceramic monolithic crown systems of different thickness. J Oral Sci. 2015;57:255-261.

[2] Rekow ED, Silva NR, Coelho PG, et al. Performance of dental ceramics: challenges for improvements. J Dent Res. 2011;90:937-952.

[3] Wang H, Liao Y, Chao Y, et al. Shrinkage and strength characterization of an alumina-glass interpenetrating phase composite for dental use. Dent Mater. 2007;23:1108-1113.

[4] Kurbad A, Reichel K. Multicolored ceramic blocks as an esthetic solution for anterior restorations. Int J Comput Dent. 2006;9:69-82.

[5] Bakeman EM, Rego N, Chaiyabutr Y, et al. Influence of ceramic thickness and ceramic materials on fracture resistance of posterior partial coverage restorations. Oper Dent. 2015;40:211-217.

[6] Fradeani M, Aquilano A, Bassein L. Longitudinal study of pressed glass-ceramic inlays for four and a half years. J Prosthet Dent. 1997;78:346-353.

[7] Valandro LF, Mallmann A, Della Bona A, et al. Bonding to densely sintered alumina and glass infiltrated aluminum zirconium based ceramics. J Appl Oral Sci. 2005;13:47-52.

[8] Souza ROA, Castilho AA, Fernandes VVB, et al. Durability of microtensile bond to nonetched and etched feldspar ceramic: self-adhesive resin cements vs. conventional resin. J Adhes Dent. 2011;13:155-162.

[9] Passos SP, Kimparab ET, Botino MA, et al. Bond strength of different resin cement and ceramic shades bonded to dentin. J Adhes Dent. 2003;15:461-466.

[10] Passos SP, Souza ROA, Michida SMA, et al. Effects of cement-curing mode and light-curing unit on the bond durability of ceramic cemented to dentin. Braz Oral Res. 2013;27:169-175.

[11] Van Dijken JW, Hasselrot L, Ormin A, et al. Restorations with extensive dentin/enamel-bonded ceramic coverage. A 5-year follow-up. Eur J Oral Sci. 2001;109:222-229.

[12] Chaiyabutr Y, Kois JC, Lebeau D, et al .Effect of abutment tooth color, cement color, and ceramic thickness on the resulting optical color of a CAD/CAM glass-ceramic lithium disilicatereinforced crown. J Prosthet Dent. 2011;105:83-90.

[13] Kaytan B, Onal B, Pamir T, et al. Clinical evaluation of indirect resin composite and ceramic onlays over a 24-month period. Gen Dent. 2005;53:329-334.

[14] Naeselius K, Arnelund CF, Molin MK. Clinical evaluation of all-ceramic onlays: a 4-year retrospective study Int J Prosthodont. 2008;21:40-44.

[15] Felden A, Schmalz G, Federlin M, et al. Retrospective clinical investigation and survival analysis on ceramic inlays and partial ceramic crowns: results up to 7 years. Clin Oral Invest. 1998;2:161-167.

[16] Hayashi M, Tsuchitani Y, Kawamura Y, et al. Eight-year clinical evaluation of fired ceramic inlays. Oper Dent. 2000;25:473-481.

[17] Layton DM, Walton TR. The up to 21-year clinical outcome and survival of feldspathic porcelain veneers: accounting for clustering. Int J Prosthodont. 2012;25:604-612.

[18] Van Dijken JW, Hasselrot L. A prospective 15-year evaluation of extensive dentin-enamelbonded pressed ceramic coverages. Dent Mater. 2010;26:929-939.

[19] Friedl KH, Schmalz G, Hiller KA, et al. In-vivo evaluation of a feldspathic ceramic system: 2-year results. J Dent. 1996;24:25-31.

[20] Santos MJ, Mondelli RF, Francischone CE, et al. Clinical evaluation of ceramic inlays and onlays made with two systems: a one-year follow-up. J Adhes Dent. 2004;6:333-338.

[21] Salazar Marocho SM, de Melo RM, Macedo LGS, et al. Strength of a feldspar ceramic according to the thickness and polymerization mode of the resin cement coating. Dent Mater J. 2011;30: 323-329.

[22] Ozcan M, Vallittu PK. Effects of surface conditioning methods on the bond strength of luting cement to ceramics. Dent Mater. 2003;19:725-731. 
[23] Cavel WT, Kelsey WP, Barkmeier WW, et al. A pilot study of the clinical evaluation of castable ceramic inlay and a dual-cure resin cements. Quintessence Int. 1988;19:257-262.

[24] Akgungor G, Akkayan B, Gaucher H. Influence of ceramic thickness and polymerization mode or a resin lutin agent on early bond strength and durability with a lithium disilicate-based ceramic system. J Prosthet Dent. 2005;94:234-241.

[25] Cho SH, Lopez A, Berzins DW, et al. Effect of different thicknesses of pressable ceramic veneers on polymerization of light-cured and dual-cured resin cements. J Contemp Dent Pract. 2015;16:347-352.

[26] Ayres AP, Andre CB, Pacheco RR, et al. Indirect restoration thickness and time after lightactivation effects on degree of conversion of resin cement. Braz Dent J. 2015;26:363-367.

[27] El-Mowafy OM, Rubo MH. Influence of composite inlay/onlay thickness on hardening of dualcured resin cements. J Can Dent Assoc. 2000;66:147.

[28] Lee BI, Na W, Chang J, et al. Influence of ceramic thickness and curing mode on the polymerization shrinkage kinetics of dual-dured resin cements. Dent Mater. 2008;24:1141-1147.

[29] Amaral R, Özcan M, Bottino MA, et al. Microtensile bond strength of a resin cement to glass infiltred zircônia-reinforced ceramic: the effect of surface conditioning. Dent Mater. 2006;22:283-290.

[30] Phrukkanon S, Burrow MF, Tyas MJ. Effect of cross-sectional surface area on bond strengths between resin and dentin. Dent Mater. 1998;14:120-128.

[31] Bottino MA, Valandro LF, Scotti R, et al. Effect of surface treatments on the resin bond to zirconium-based ceramic. Int J Prosthodont. 2005;18:60-65.

[32] Pashley DH, Carvalho RM, Sano H, et al. The microtensile bond test: a review. J Adhes Dent. 1999;1:299-309.

[33] Hasegawa EA, Boyer DB, Chan DC. Hardening of dual-cured cements under composite resin inlays. J Prosthet Dent. 1991;66:187-192.

[34] Peters AD, Meiers JC. Effect of polymerization mode of a dual-cured resin cement on timedependent shear bond strength to porcelain. Am J Dent. 1996;9:264-268.

[35] Barghi N, McAlister EH. LED and halogen lights: effect of ceramic thickness and shade on curing luting resin. Compend Contin Educ Dent. 2003;24:497-500.

[36] Koch A, Kroeger M, Hartung M, et al. Influence of ceramic translucency on curing efficacy of different light-curing units. J Adhes Dent. 2007;9:449-462.

[37] Rueggeberg FA, Caughman WF, Curtis JW, Jr. Effect of light intensity and exposure duration on cure of resin composite. Oper Dent. 1994;19:26-32.

[38] Silva NRFA, de Souza GM, Coelho PG, et al. Effect of water storage time and composite cement thickness on fatigue of a glass-ceramic trilayer system. J Biomed Mater Res B Appl Biomater. 2008;84B:117-123.

[39] Al-Salehi SK, Burke FJ. Methods used in dentin bonding tests: an analysis of 50 investigations on bond strength. Quintessence Int. 1997;28:717-723.

[40] Hariri I, Shimada Y, Sadr A, et al. The effects of aging on shear bond strength and nanoleakage expression of an etch-and-rinse adhesive on human enamel and dentin. J Adhes Dent. 2012;14:235-243.

[41] Erickson RL, Glasspoole EA, Rtief DG. Influence of test parameters on dentin bond strength measurements. J Dent Res. 1989;68:1543-1548.

[42] Huang M, Thompson VP, Rekow ED, et al. Modeling of water absorption induced cracks in resin-based composite supported ceramic layer structures. J Biomed Mater Res B Appl Biomater. 2008;84B:124-130.

[43] Della Bona A, van Noort R. Shear vs. tensile bond strength of resin composite bonded to ceramic. J Dent Res. 1995;74:1591-1596.

[44] Sano H, Shono H, Sonoda J, et al. Relationship between surface area for adhesion and tensile bond strength: evaluation of a microtensile bond test. Dent Mater. 1994;10:236-240.

[45] El-Mowafy OM, Rubo MH, El-Badrawy WA. Hardening of new resin cement cured through a ceramic inlay. Oper Dent. 1999;24:38-44.

[46] Cavalcanti AN, Foxton RM, Watson TF, et al. Bond strength of resin cements to a zirconia ceramic with different surface treatments. Oper Dent. 2009;34:280-287. 
[47] Kumbuloglu O, Lassila LVJ, User A, et al. Shear bond strength of composite resin cements to lithium disilicate ceramics. J Oral Rehabil. 2005;32:128-133.

[48] Rasetto FH, Driscoll CF, Prestipino V, et al. Light transmission through all-ceramic dental materials: a pilot study. J Prosthet Dent. 2004;91:441-446.

[49] Fan PL, Schumacher RM, Azzolin K, et al. Curing- light intensity and depth of cure of resin-based composites tested according to international standards. J Am Dent Assoc. 2002;133:429-434.

[50] Lopes C, Rodrigues RB, Silva AL, et al. Degree of conversion and mechanical properties of resin cements cured through different all-ceramic systems. Braz Dent J. 2015;26:484-489.

[51] Soderholm KJM, Roberts MJ. Influence of water exposure on the tensile strength of composites. J Dent Res. 1990;69:1812-1816.

[52] Hooshmand T, van Noort R, Keshvad A. Bond durability of the resin bonded and silane treated ceramic surface. Dent Mater. 2002;18:179-188. 